\title{
The STEL induction magnetometer network for observation of high-frequency geomagnetic pulsations
}

\author{
K. Shiokawa ${ }^{1}$, R. Nomura ${ }^{1}$, K. Sakaguchi ${ }^{1}$, Y. Otsuka ${ }^{1}$, Y. Hamaguchi ${ }^{1}$, M. Satoh ${ }^{1}$, Y. Katoh ${ }^{1}$, \\ Y. Yamamoto ${ }^{1}$, B. M. Shevtsov ${ }^{2}$, S. Smirnov ${ }^{2}$, I. Poddelsky ${ }^{2}$, and M. Connors ${ }^{3}$ \\ ${ }^{1}$ Solar-Terrestrial Environment Laboratory, Nagoya University, Nagoya, Japan \\ ${ }^{2}$ Institute of Cosmophysical Research and Radiowave Propagation, \\ Far Eastern Branch of the Russian Academy of Sciences, \\ Russian Federation \\ ${ }^{3}$ Center for Science, Athabasca University, Athabasca, Canada
}

(Received February 12, 2010; Revised May 17, 2010; Accepted May 17, 2010; Online published August 6, 2010)

\begin{abstract}
The Solar-Terrestrial Environment Laboratory (STEL) induction magnetometer network has been developed to investigate the propagation characteristics of high-frequency geomagnetic pulsations in the Pc1 frequency range $(0.2-5 \mathrm{~Hz})$. Five induction magnetometers were installed in the period 2005-2008 at Athabasca in Canada, Magadan and Paratunka in Far East Russia, and Moshiri and Sata in Japan. The sensitivity of these magnetometers is between 0.3 and $13 \mathrm{~V} / \mathrm{nT}$ at turnover frequencies of $1.7-5.5 \mathrm{~Hz}$. GPS time pulses are used for accurate triggering of the $64-\mathrm{Hz}$ data sampling. We show examples of $\mathrm{PiB} / \mathrm{Pc} 1$ magnetic pulsations observed at these five stations, as well as the harmonic structure of ionospheric Alfvén resonators observed at Moshiri. We found that the Pc1 packets are slightly modulated as they propagate from high to low latitudes in the ionospheric duct. These network observations are expected to contribute to our understanding of Pc1-range magnetic pulsations and their interaction with relativistic electrons by combining the obtained results with future satellite missions that observe radiation belt particles.
\end{abstract}

Key words: Induction magnetometer, Pc1, ULF wave, ground network, ionospheric Alfvén resonator.

\section{Introduction}

Ground magnetometer networks are a powerful tool for investigating the global characteristics of Earth's magnetosphere and ionosphere. Compared to other groundbased instruments, magnetometers are rather simple, and their well-established methods allow conducting multipoint routine measurements at remote field sites. Recently, several networks using fluxgate magnetometers with a sampling rate of the order of $1 \mathrm{~s}$ have been developed. They cover the Japanese longitudinal sector and global equatorial latitudes (210MM: Yumoto and the 210MM Magnetic Observation Group, 1996, CPMN: Yumoto and the CPMN Group, 2001, and MAGDAS: Yumoto and the MAGDAS Group, 2006), over Canada and North America (THEMIS: Russell et al., 2008; CARISMA: Mann et al., 2008; MACCS: Engebretson et al., 1995; and McMAC: http://spc.igpp.ucla.edu/mcmac/), South America (SAMBA: http://samba.atmos.ucla.edu/), and Europe (IMAGE: Lühr, 1994; SAMNET: Yeoman et al., 1990; and SEGMA: Vellante et al., 2002). However, networks of induction magnetometers with higher sampling rates have not been well developed, with the exception of networks in Finland and Greece (e.g., Bösinger et al., 2002; Yahnin et al., 2009), Svalbard (Engebretson et al., 2009),

Copyright (c) The Society of Geomagnetism and Earth, Planetary and Space Sciences (SGEPSS); The Seismological Society of Japan; The Volcanological Society of Japan; The Geodetic Society of Japan; The Japanese Society for Planetary Sciences; TERRAPUB.

doi: $10.5047 /$ eps.2010.05.003
Canada (e.g., Hayashi et al., 1988; Lessard et al., 2006; Mann et al., 2008), and Antarctica (e.g., Engebretson et al., 2002). As described in this paper, we are developing a network mainly in the Japanese longitudinal sector.

Induction magnetometers can measure Pc1 pulsations of the geomagnetic field with a frequency range of $0.2-5 \mathrm{~Hz}$. Pulsations in this frequency range usually remain undetected by fluxgate magnetometers due to their lower sampling rates and higher noise levels. Although research targeting these higher-frequency pulsations by using induction magnetometers has been conducted since the 1960 s, the focus has recently been shifted for the following reasons: 1) pulsations can be an accurate indicator of substorm onset timing as PiB/Pi1 bursts (e.g., Lessard et al., 2006; Posch et al., 2007; Milling et al., 2008), 2) Pc1 pulsations, which represent electromagnetic ion cyclotron (EMIC) waves in the inner magnetosphere, can be a loss mechanism of relativistic electrons in the outer radiation belt involving pitchangle scattering of such electrons into the loss cone (e.g., Thorne and Kennel, 1971; Sandanger et al., 2007; Miyoshi et al., 2008), and 3) ionospheric Alfvén resonators (IARs) in the Pc1 frequency range, which occur due to a local minimum of the Alfvén velocity in the $F$-region ionosphere, can be utilized as a monitor of the density structure of the topside ionosphere and in the auroral acceleration region, on the basis of ground observations (e.g., Bösinger et al., 2002; Pilipenko et al., 2002; Hebden et al., 2005). Advances in the size of computer hard disks in the last 15 years have made it possible to record digital data at higher sampling 


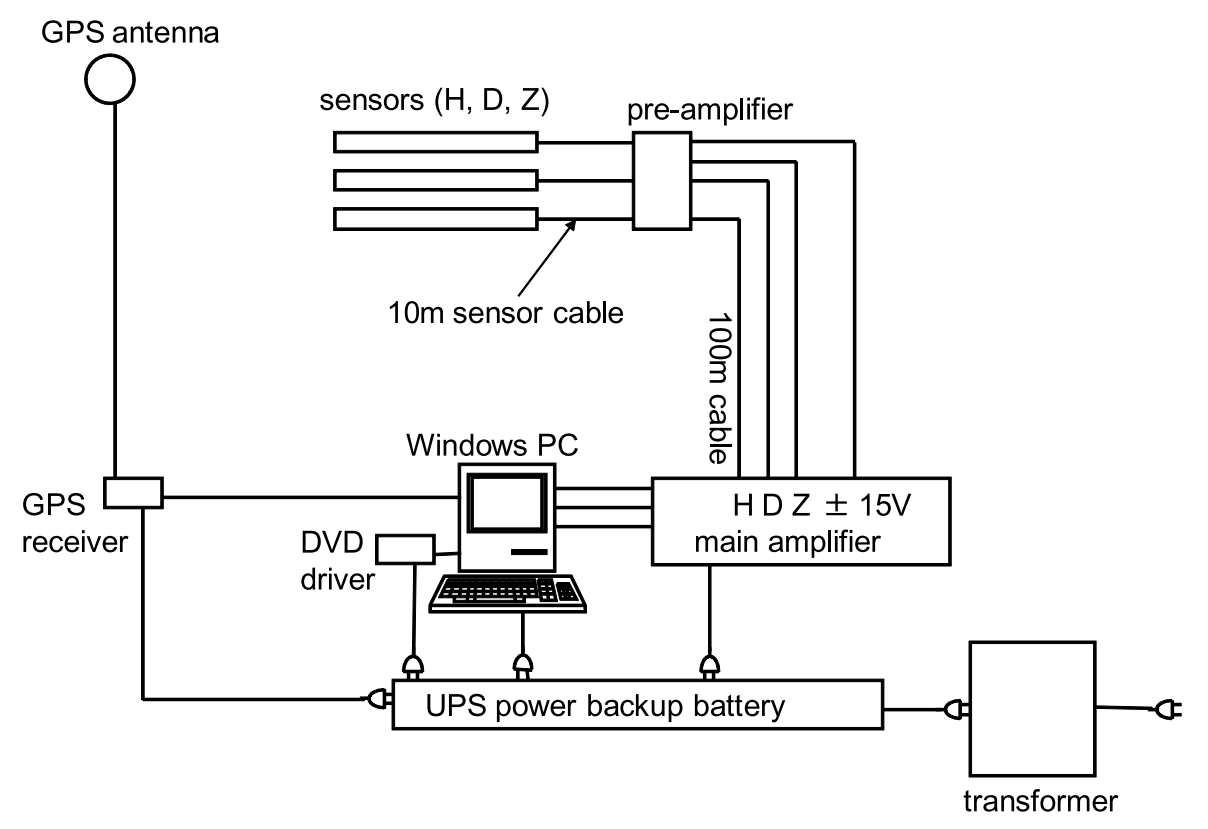

Fig. 1. Induction magnetometer system used in the network. A pre-amplifier is not used at Athabasca.

rates. Furthermore, GPS satellite signals enable accurate sampling and absolute timing of magnetometer data even at remote field stations.

In this paper, we describe the instrumentation and calibration of a newly developed induction magnetometer chain installed at Athabasca (ATH), Canada, Magadan (MGD) and Paratunka (PTK) in Far East Russia, and Moshiri (MSR) and Sata (STA) in Japan. We also present examples of $\mathrm{PiB}$ and $\mathrm{Pc} 1$ pulsations as well as IAR signatures observed at these stations in order to demonstrate the data quality and the capabilities of these magnetometers.

\section{Instrumentation}

Figure 1 shows the induction magnetometer system used in the network. The sensors at MGD, PTK, MSR, and STA, which were made by Tierra Tecnica, Tokyo, Japan, have 100,000 or 200,000 turns per permalloy core. The sensors at ATH are in fact induction sensors reused from the STEP polar magnetometer network in Canada. The sensors at MSR and STA were originally made in 1989-1992 to observe Pi2/Pc3 pulsations. The sensors of MGD and PTK were newly made to construct this chain. The pre-amplifier and the amplifier at MSR were designed by Tierra Tecnica. The pre-amplifiers and the main amplifiers at ATH, MGD, PTK, and STA were designed by the Solar-Terrestrial Environment Laboratory (STEL), Nagoya University; so their frequency response is different from that at MSR, as shown later. At ATH, we do not use a pre-amplifier. The three sensors were installed in the geomagnetic $H, D$, and $Z$ directions at all stations, where $H$ denotes the horizontal direction of the geomagnetic field, $D$ is perpendicular to the horizontal geomagnetic field in the horizontal plane, and $Z$ denotes the vertical direction.

All the data recording systems were made by STEL. They have GPS receivers that generate $64-\mathrm{Hz}$ standard time pulses from the original 1 PPS (1 pulse per second) GPS signal in order to trigger $64-\mathrm{Hz}$ sampling of the three- component magnetometer data. At ATH, the 64-Hz sampling was initially triggered by the internal clock of a personal computer up to March 14, 2008, after which it was triggered by a GPS signal. The error of the GPS time pulse from the absolute clock is less than $\pm 1 \mu \mathrm{s}$. The 1 PPS signal from the GPS receiver is also recorded in the data as the standard time signal for all stations. The GPS receiver is also used to correct the clock of the personal computer every 10 minutes. The clock information generated by the personal computer is written into a data file every $4 \mathrm{~s}$.

The power supply of all these systems is ensured by a UPS battery. A two-coil transformer is used to avoid damage to the instruments due to surge currents from the power line, which are most often induced by lightning. At ATH, MGD, and PTK, we also need the transformers to adjust the voltage of the power line, since the system is designed in Japan with a $100 \mathrm{~V}$ AC power. All the data are recorded onto the hard disk of the personal computer. The data files at ATH, PTK, MSR, and STA are routinely transferred to STEL through the internet, and an additional backup is stored on DVD disks. The data from MGD are transferred to STEL by mailing the DVD disks.

Figure 2 shows images of the instruments at ATH and MGD. The magnetometer sensors are buried underground. Through 100-m coaxial shield cables, the signal is transferred to the main amplifier and the personal computer inside the local control building. In addition, a 2-m calibration coil is used to obtain the frequency response of the magnetometers before installation, as described in the next section.

\section{Calibration of the Magnetometers}

The frequency dependence of the sensitivity of the induction magnetometer system and its phase delay were calibrated by superimposing sinusoidal magnetic field fluctuations by using the calibration coil shown in the top left panel of Fig. 2. The calibration coil (100 turns/m) has a 


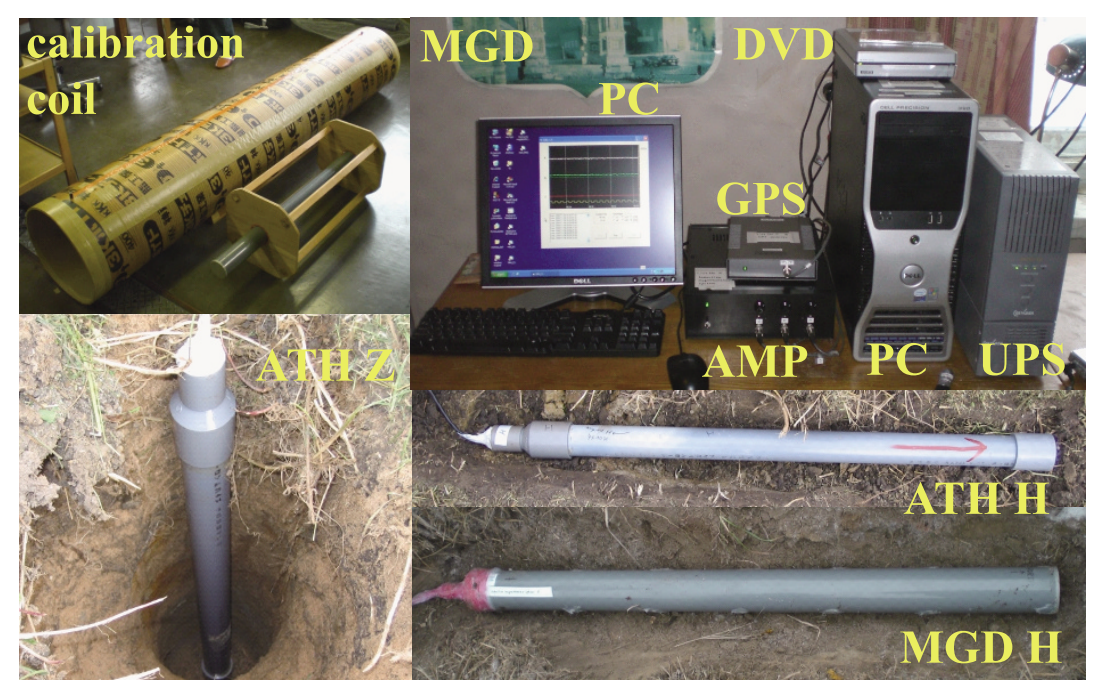

Fig. 2. Photographs of the induction magnetometer system at Magadan (MGD) and Athabasca (ATH) and a 2-m coil used for calibration.

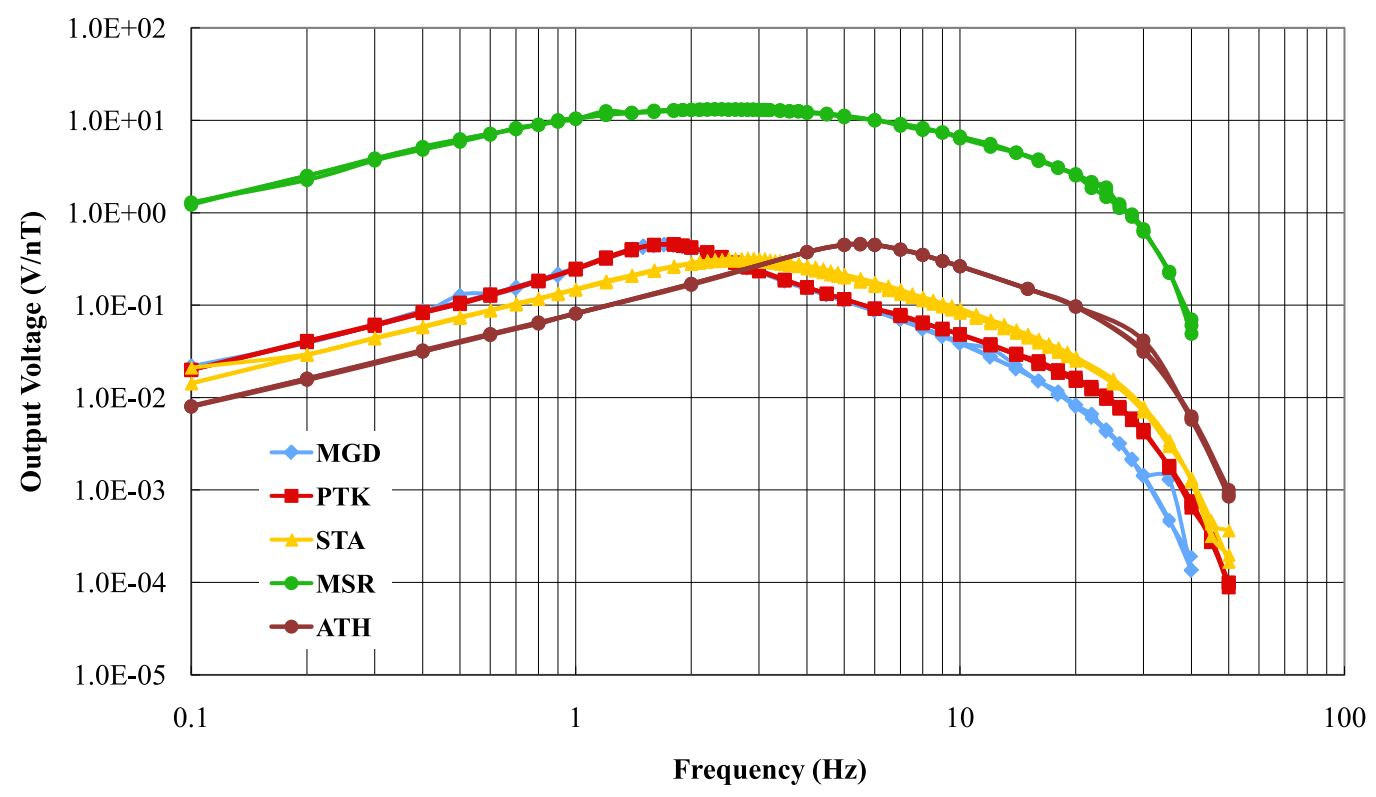

Fig. 3. Sensitivities of the induction magnetometers used at the five stations. The sensitivities for the $H, D$, and $Z$ components are drawn in the same color and are nearly identical for each station.

length of $2 \mathrm{~m}$ and a diameter of $0.4 \mathrm{~m}$. The magnetic field intensity at the center of the coil for a given electric current was calculated considering the finite length of the coil. The magnetometer sensor, which has a length of $\sim 1 \mathrm{~m}$, is inserted into the center of the calibration coil.

Figure 3 shows the frequency dependence of the magnetometer sensitivity in units of output voltage from the magnetometer versus the amplitude of the superimposed magnetic field in $\mathrm{nT}$. The dependences for the $H, D$, and $Z$ components are shown in the same color and are nearly identical for each station since the sensors and the amplifiers were made in accordance with the same specifications. The main amplifier of the magnetometer has a gain that can be used for changing the sensitivity. The curves in Fig. 3 are drawn for the actual gain values used at these sites. The random errors of these curves are less than $1 \%$ around the peak frequencies, while they increase to more than $10 \%$ at higher frequencies when the output of the sensor becomes small.

At low frequencies, the sensitivity increases as the frequency is increased, as a natural response of the induction coil. After reaching a peak at $1.7-5.5 \mathrm{~Hz}$, the sensitivity decreases as the frequency is increased due to the frequency dependence of the pre-amplifier and the main amplifier. In this regard, the sensitivity at MSR is an order higher than that of the other stations, and the shape of its curve is slightly different. This is caused by the fact that the amplifier at MSR is different from that at the other stations. The sensitivities have peaks at $0.3-13.2 \mathrm{~V} / \mathrm{nT}$ at $1.7-5.5 \mathrm{~Hz}$. Table 1 summarizes the peak sensitivities and their frequencies (turnover frequencies) for all five stations.

Figure 4 shows the frequency dependence of the phase delay of the magnetometers with respect to the superimposed magnetic field fluctuations. The dependences for the 
Table 1. Station Locations, peak sensitivity, and polarity of the induction magnetometers. Dipole geomagnetic latitudes are calculated using the IGRF-11 model at epoch 2010.

\begin{tabular}{|c|c|c|c|c|c|c|c|c|}
\hline Station & Abb. & Geographic latitude & Geographic longitude & Magnetic latitude & Peak sensitivity & \multicolumn{3}{|c|}{ Positive polarity } \\
\hline Athabasca & ATH & 54.7 & 246.7 & 61.6 & $0.455 \mathrm{~V} / \mathrm{nT}$ at $5.5 \mathrm{~Hz}$ & north & east & up \\
\hline Magadan & MGD & 60.0 & 150.9 & 52.2 & $0.450 \mathrm{~V} / \mathrm{nT}$ at $1.7 \mathrm{~Hz}$ & north & east & down \\
\hline Paratunka & PTK & 52.9 & 158.3 & 46.0 & $0.450 \mathrm{~V} / \mathrm{nT}$ at $1.8 \mathrm{~Hz}$ & north & east & down \\
\hline Moshiri & MSR & 44.4 & 142.3 & 35.9 & $13.2 \mathrm{~V} / \mathrm{nT}$ at $2.6 \mathrm{~Hz}$ & south & west & up \\
\hline Sata & STA & 31.0 & 130.7 & 21.7 & $0.314 \mathrm{~V} / \mathrm{nT}$ at $2.5 \mathrm{~Hz}$ & north & east & down \\
\hline
\end{tabular}

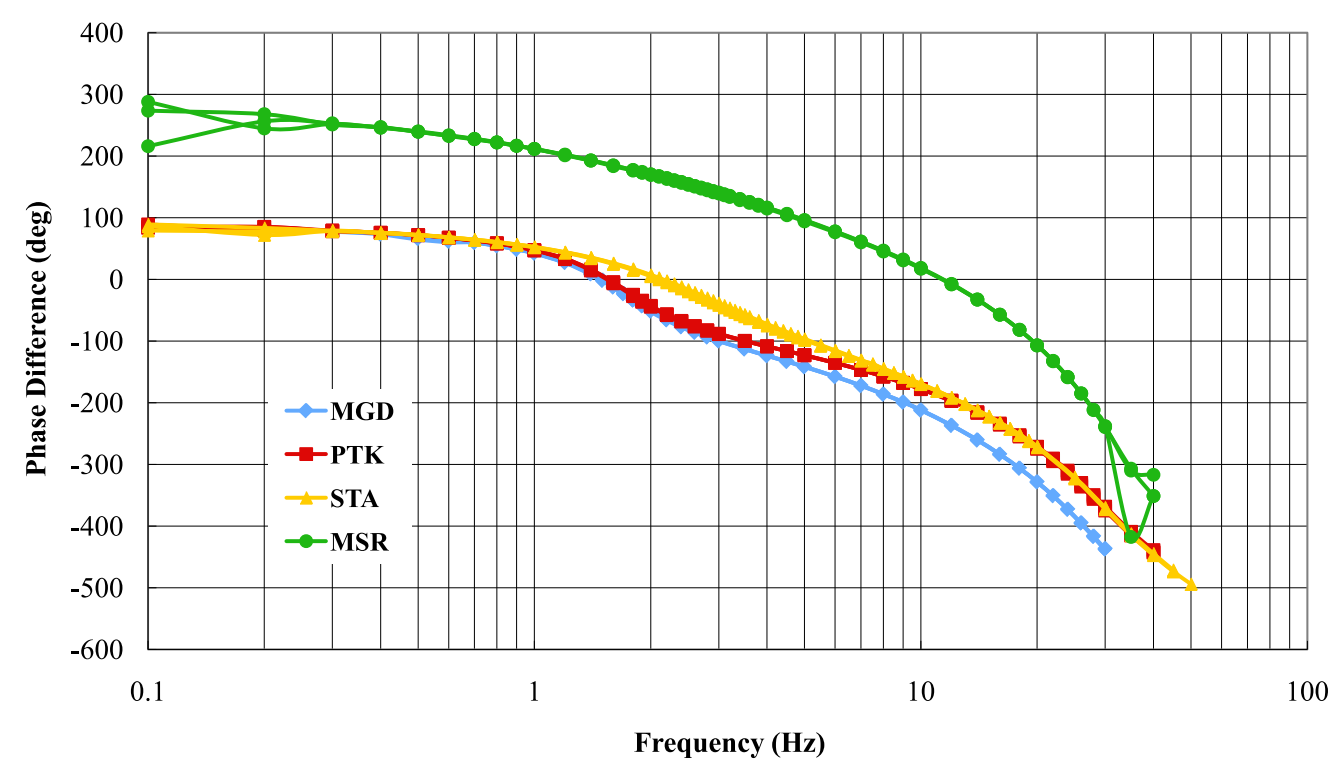

Fig. 4. Phase difference between the superimposed magnetic field fluctuations and the output from the induction magnetometer systems for all five stations. The phase differences for the $H, D$, and $Z$ components are drawn in the same color and are nearly identical for each station.

$H, D$, and $Z$ components are again shown in the same color and are nearly identical for each station. We did not calibrate the phase delay of the magnetometer at ATH. The phase delay generally decreases as the frequency is increased, as a natural response of the induction coil and the amplifiers. Furthermore, the phase delay is similar for all stations except MSR, whose phase delay differs by about $180^{\circ}$ from that of the other stations. The output polarities with respect to the directions of the superimposed magnetic field are summarized in Table 1. These polarities were determined by introducing a step-like increase of the magnetic field to the sensor.

\section{Observations and Discussion}

Figure 5 shows a map of the stations and the month when routine observations were started. The geographic latitudes and longitudes and dipole geomagnetic latitudes of these stations are listed in Table 1. The chains at MGD, PTK, MSR, and STA are mostly in geomagnetic latitudinal direction between $L=2.7$ and $L=1.2$. ATH is located at $L=4.4$, which is suitable for observing EMIC waves occurring near the plasmapause. The magnetometer at ATH began observation on September 4, 2005, while the magnetometers at the other stations were installed in 2007-2008.

Figure 6 shows the dynamic spectra of the $H$ component of the magnetic field fluctuations at $0.1-32 \mathrm{~Hz}$ as obtained by the five magnetometers on February 27, 2009. The local midnight at MGD, PTK, MSR, and STA was at $\sim 13-$
$15 \mathrm{UT}$, and the local midnight at ATH was at $\sim 8 \mathrm{UT}$. These dynamic spectra were obtained by calculating the Fourier transform of the raw magnetic field data with a time window of $128 \mathrm{~s}$ (8192 data points).

An intense PiB burst was observed at 0920-1300 UT at ATH at a frequency range below $1 \mathrm{~Hz}$, indicating substorm activity. In fact, the provisional $\mathrm{AE}$ index provided by WDC-C2 for geomagnetism at Kyoto University indicates that substorms took place at $0910 \mathrm{UT}$ and $1215 \mathrm{UT}$ with peak AE indices of $\sim 600 \mathrm{nT}$ and $\sim 900 \mathrm{nT}$, respectively. At 1000-1030 UT, a clear enhancement of the power spectral density (PSD) was observed at MGD, PTK, and MSR at a frequency range of $0.1-2 \mathrm{~Hz}$. Since the peak frequency tends to increase with time, it is likely that this Pc1 pulsation event corresponds to the intervals of pulsations of diminishing periods (IPDP) associated with the EMIC waves generated by ring current ions in the magnetospheric equatorial plane, which are in turn associated with the substorm at 0910 UT (e.g., Kangas et al., 1998 and references therein). The corresponding enhancement of the PSD can also be recognized at STA in the same interval at 10001030 UT, albeit with weaker intensity, even though the data at STA are affected by strong broadband noise at $1-10 \mathrm{~Hz}$. The spectra at PTK are also affected by spiky noise, probably from nearby facilities in the observatory.

In Fig. 6, the PSD shows continuous enhancement at frequencies centered at $\sim 8 \mathrm{~Hz}$ throughout the plotted interval at ATH and MSR, since the sensitivity at $8 \mathrm{~Hz}$ is high for 


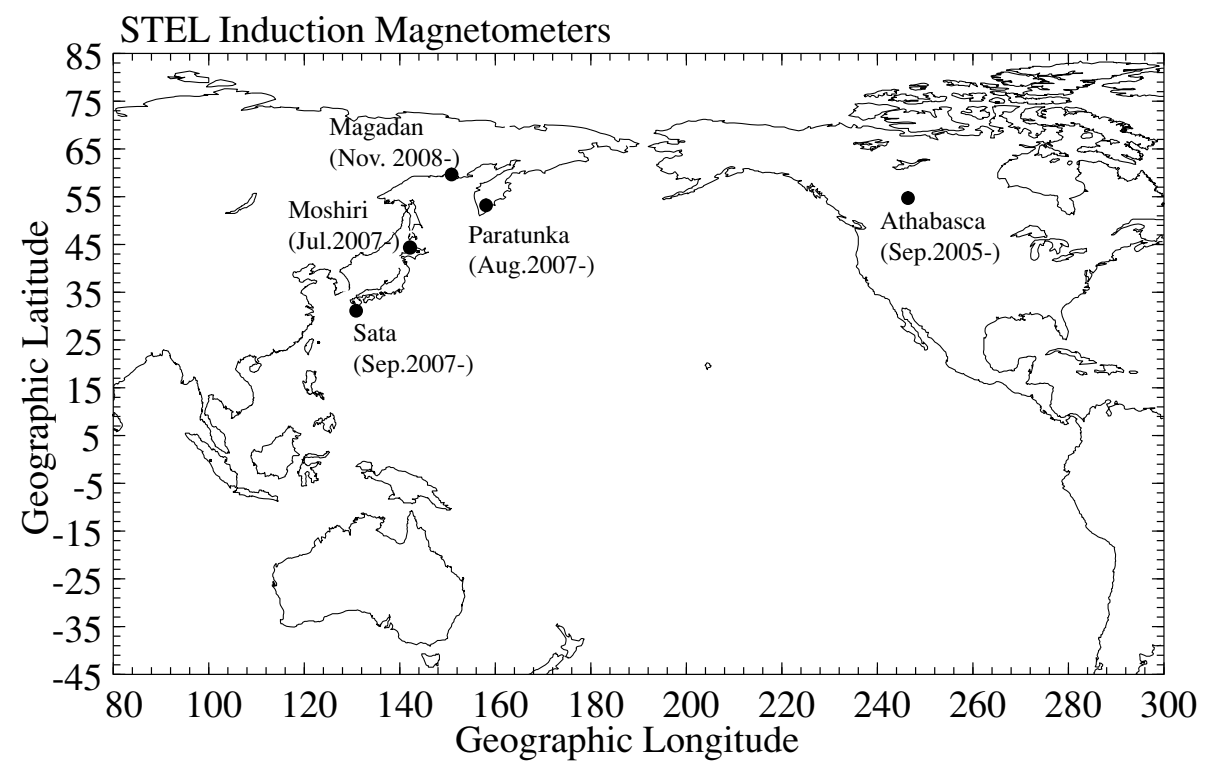

Fig. 5. Map showing the current stations of the STEL induction magnetometer network.

the magnetometers at MSR and ATH, as shown in Fig. 3. This $\sim 8 \mathrm{~Hz}$ oscillation is known as the Schumann resonance, which is caused by a global-scale resonance of ELF waves in the waveguide between Earth's ionosphere and the ground.

Although PiB waves are predominantly observed at ATH for this event, Pc1 bands with frequencies of $0.3-1 \mathrm{~Hz}$ are also observed at ATH $(L=4.4)$ fairly often since the site is located near the footprint of the ordinary plasmapause, where EMIC waves tend to occur. Sakaguchi et al. (2007, 2008) have shown that there exists a one-to-one correspondence between these Pc1 waves and isolated proton auroras observed simultaneously by an all-sky imager at ATH. In addition, Miyoshi et al. (2008) have shown that precipitation of relativistic electrons observed by the NOAA satellite was associated with a Pc1 wave and an isolated proton aurora observed at ATH.

Figure 7 shows the waveforms of the $H$ component of the magnetic field fluctuations observed at 1028:001030:00 UT on February 27, 2009 during the strong $\mathrm{PiB} / \mathrm{Pc} 1$ event shown in Fig. 6. The vertical scale at the left of the panel is calculated at the peak sensitivity of each station. Clear sinusoidal Pc1 waves were observed at MGD, PTK, and MSR. In the STA data, similar sinusoidal wave signatures with smaller amplitudes can be recognized, although the data contains considerable noise at higher frequencies. It is likely that this small Pc1 amplitude at STA is due to the attenuation of Pc1 waves during duct propagation in the ionosphere from high to low latitudes (e.g., Greifinger and Greifinger, 1968; Kuwashima et al., 1981). Since the $\mathrm{PiB}$ waves at $\mathrm{ATH}$ are irregular low-frequency (below $1 \mathrm{~Hz}$ ) pulsations, the waveform at ATH exhibits non-sinusoidal fluctuations.

The Pc1 waves observed at MGD, PTK, and MSR constitute packet-like structures with repetition periods of 10-20 s, which are known as pearl structures (e.g., Troitskaya and Guglielmi, 1967; Mursula et al., 2001). Although these Pc1 packets appear nearly simultaneously at
MGD, PTK, and MSR, a closer inspection of the data reveals timing differences between these packet structures with a delay of about half a cycle between MGD-PTK and PTK-MSR. This timing delay indicates the propagation of the Pc1 waves from a high-latitude source region to lower latitudes through an ionospheric duct. By conducting cross-correlation analysis, the delays between MGD-PTK and PTK-MSR were estimated to be $\sim 0.3 \mathrm{~s}$ and $\sim 0.7 \mathrm{~s}$, respectively. The angle of the major axis of this $\mathrm{Pc} 1$ is $\sim 30^{\circ}, \sim 10^{\circ}$, and $\sim-10^{\circ}$ from the magnetic North (eastward positive) pole at 1030 UT at MGD, PTK, and MSR, respectively. Assuming a plane wave propagating in the magnetic North-South direction, the timing differences between MGD-PTK and PTK-MSR give a phase velocity of $2300 \mathrm{~km} / \mathrm{s}\left(=6.2^{\circ}\right.$ in magnetic latitude $\left./ 0.3 \mathrm{~s}\right)$ and $1600 \mathrm{~km} / \mathrm{s}\left(=10.1^{\circ} / 0.7 \mathrm{~s}\right)$, respectively. These values are consistent with the typical Pc1 phase velocity of $500-2500 \mathrm{~km} / \mathrm{s}$, as estimated by Fraser (1975). The smaller density of the $F$-region during the solar minimum can increase the ducting Alfvén velocity. A decrease in velocity at lower latitudes is also expected for higher densities of the $F$-region at lower latitudes.

In Fig. 7, we also noticed that the Pc1 packets are slightly modulated as they propagate from MGD to MSR through PTK (e.g., 1028:25 UT and 1029:40 UT). In other words, the packet shapes are somewhat dissimilar at these three stations. This fact may indicate modulation of the Pc1 pearl structure during the propagation of the ionospheric duct, or generation of the Pc1 pearl structure itself due to mixture of different waves during the propagation.

Figure 8 shows the dynamic spectra of the $H, D$, and $Z$ components of the magnetic field fluctuations at $0.1-32 \mathrm{~Hz}$ as observed at Moshiri on January 1, 2009. The spectra of the $H$ and $D$ components indicate harmonic structures in the frequency range above $0.4 \mathrm{~Hz}$ between the late afternoon $(\sim 15 \mathrm{LT})$ and the following morning $(\sim 09 \mathrm{LT})$. This is a typical signature of ionospheric Alfvén resonators (IAR), which occur due to Alfvén waves bouncing between the 


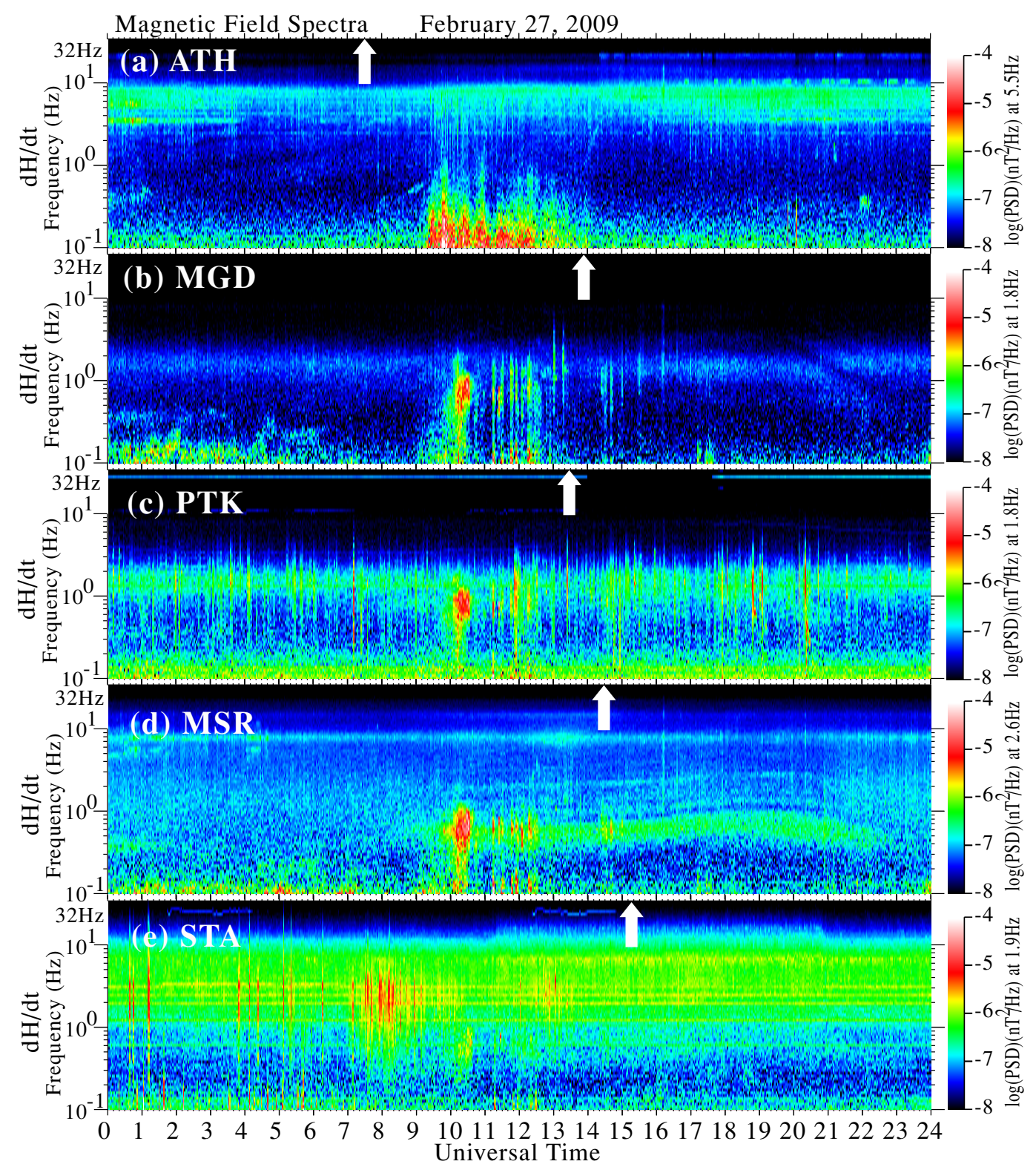

Fig. 6. Dynamic spectra of the $H$ component of the magnetic field fluctuations at $0.1-32 \mathrm{~Hz}$ as observed on February 27,2009 at the five stations from higher (top) to lower (bottom) latitudes. The unit of power spectral density (PSD) in the color scale is calculated at the peak sensitivity of each station. The local midnight at each station is indicated by a white arrow.

bottom side of the ionospheric $F$-layer and the top side of the ionosphere. This bouncing is associated with the local minimum of the Alfvén velocity around the density peak of the $F$-layer (e.g., Polyakov and Rapoport, 1981; Belyaev et al., 1990; Lysak, 1993; Pokhotelov et al., 2001). These harmonic structures are observed at MSR almost every night since the noise level at MSR is lowest in comparison to that at the other stations. Similar IAR signatures have also been observed at all other stations when the noise level is not high (e.g., see Parent et al., 2006 for IAR signatures at ATH). With an appropriate IAR model, these harmonic structures can be used to obtain density information about the top side of the ionosphere (e.g., Bösinger et al., 2002). Thus, this information can be used for remote sensing of the top side of the ionosphere through ground-based observations.

\section{Summary}

We installed five induction magnetometers with turnover frequencies of $1.7-5.5 \mathrm{~Hz}$ and sensitivities of $0.3-13 \mathrm{~V} / \mathrm{nT}$ in Canada, Far East Russia, and Japan at $L=4.4-1.2$ in 2005-2008. The timing accuracy of the $64-\mathrm{Hz}$ sampling rate of the magnetometer data was guaranteed by using GPS receivers. The data from these magnetometers illustrate the possibilities for observing $\mathrm{PiB}$ and $\mathrm{Pc} 1$ pulsations as well as harmonic structures of ionospheric Alfvén resonators at these stations.

Although observational techniques based on induction magnetometers are well-established, the recent development of recording systems with computers makes it possible to obtain routine digital data at high sampling rates and with high timing accuracy at remote stations. Combining the data from these magnetometers with other new data, such as those from all-sky imagers and ionospheric 


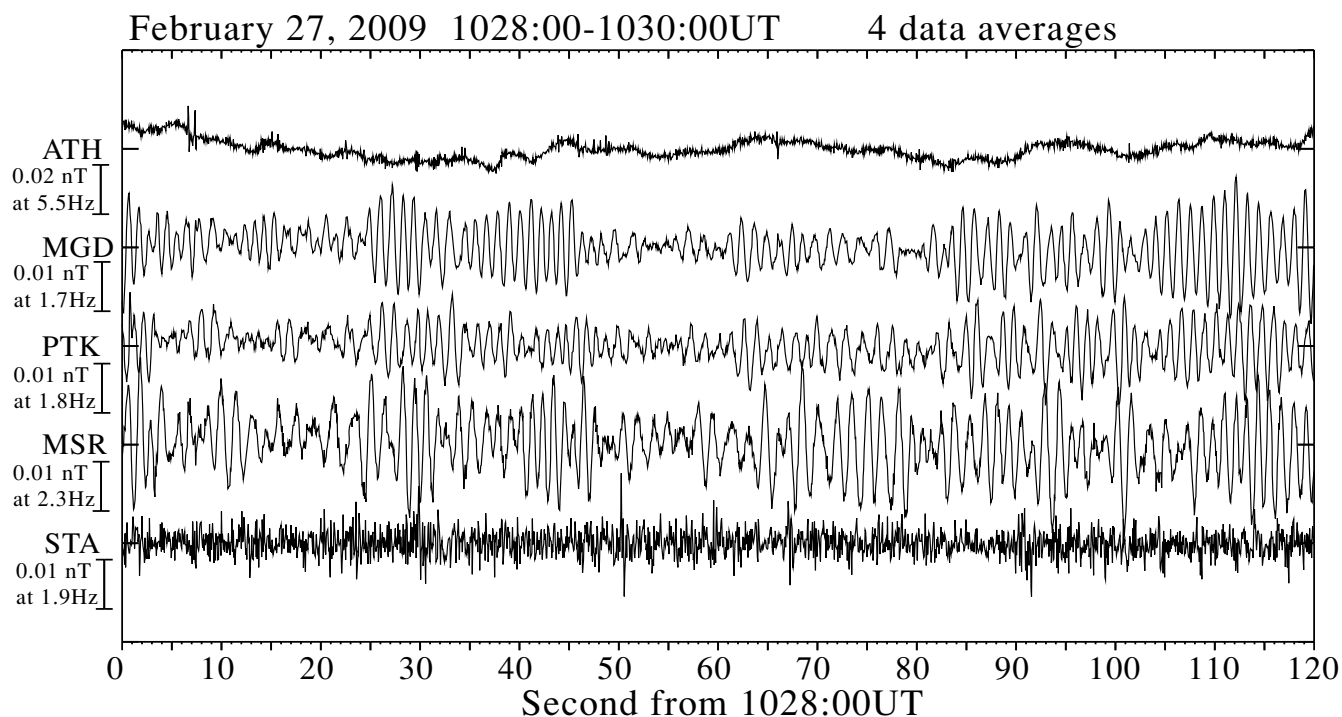

Fig. 7. The $H$ component of the magnetic field fluctuations as observed at 1028:00-1030:00 UT on February 27, 2009 at the five stations from higher (top) to lower (bottom) latitudes. The vertical scale indicated at the left side of the panel is calculated at the peak sensitivity of each station. The original data sampled at $64 \mathrm{~Hz}$ are averaged over sets of 4 data points $(16 \mathrm{~Hz})$ in order to reduce the noise. The polarity of the MSR data is reversed in order to account for the difference between the sensor polarity of the magnetometer at MSR and that of the other stations.

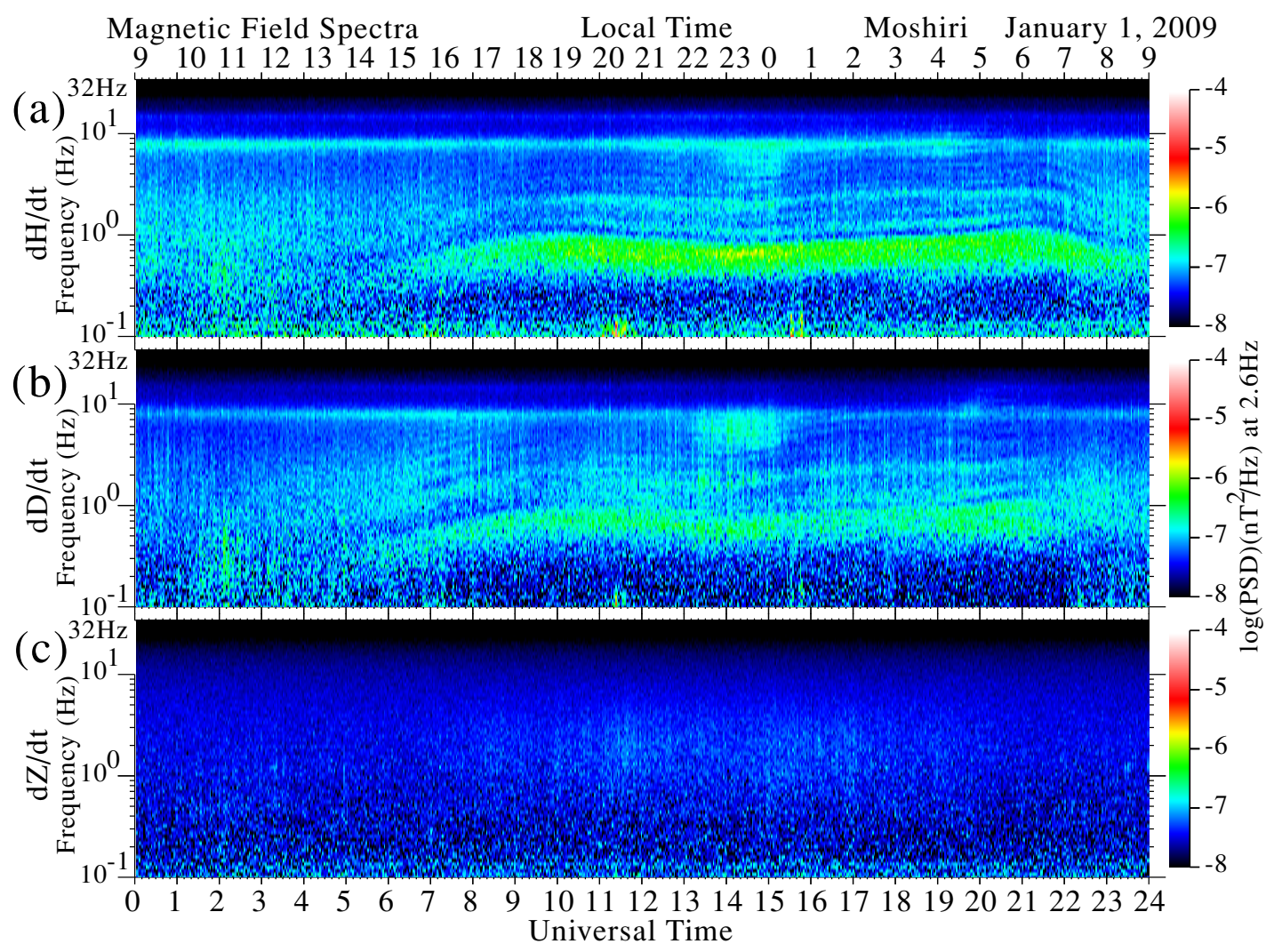

Fig. 8. Dynamic spectra of the $H, D$, and $Z$ components of the magnetic field fluctuations at $0.1-32 \mathrm{~Hz}$ as observed on January 1,2009 at Moshiri, indicating signatures of ionospheric Alfvén resonators during the night.

and magnetospheric satellites, is expected to greatly contribute to our understanding of the generation and propagation of Pc1-range pulsations. Several satellite missions, such as Energization and Radiation in Geospace (ERG) in Japan, Radiation Belt Storm Probes (RBSP) in the United States, and Outer Radiation Belt Injection, Transport, Acceleration and Loss Satellite (ORBITALS) in Canada, are going to be launched during the next solar maximum in 2012-2014 in order to investigate the generation and loss of radiation belt particles. The ground induction magnetometer network provides important information regarding the generation and propagation of EMIC waves which can cause loss of radiation belt particles in the inner magnetosphere. 
Acknowledgments. We thank $M$. Sera and Y. Ikegami at the Moshiri observatory of the Solar-Terrestrial Environment Laboratory, Nagoya University, all the staff of the Institute of Cosmophysical Research and Radiowave Propagation (IKIR), and I. Shelton and I. Schofield of Athabasca University, for their help and support regarding the operation of the induction magnetometers. This work was carried out under an agreement between IKIR and STEL on the international project "Ground and Satellite Measurements of Geospace Environment in the Far Eastern Russia and Japan". This work was supported by Grants-in-Aid for Scientific Research (16403007, 18403011, 19403010, and 20244080), the 21th Century COE Program (Dynamics of the Sun-Earth-Life Interactive System, No. G-4), the Global COE Program of Nagoya University "Quest for Fundamental Principles in the Universe (QFPU)", and the Special Funds for Education and Research (Energy Transport Processes in Geospace) from MEXT, Japan.

\section{References}

Belyaev, P. P., S. V. Polyakov, V. O. Rapoport, and V. Y. Trakhtengerts, The ionospheric Alfvén resonator, J. Atmos. Terr. Phys., 52, 781-787, 1990. Bösinger, T., C. Haldoupis, P. P. Belyaev, M. N. Yakunin, N. V. Semenova, A. G. Demekhov, and V. Angelopoulos, Spectral properties of the ionospheric Alfvén resonator observed at a low-latitude station $(\mathrm{L}=1.3), J$. Geophys. Res., 107(A10), 1281, doi:10.1029/2001JA005076, 2002.

Engebretson, M. J., W. J. Hughes, J. L. Alford, E. Zesta, L. J. Cahill, Jr., R. L. Arnoldy, and G. D. Reeves, Magnetometer array for cusp and cleft studies observations of the spatial extent of broadband ULF magnetic pulsations at cusp/cleft latitudes, J. Geophys. Res., 100(A10), doi:10.1029/95JA00768, 1995.

Engebretson, M. J., W. K. Peterson, J. L. Posch, M. R. Klatt, B. J. Anderson, C. T. Russell, H. J. Singer, R. L. Arnoldy, and H. Fukunishi, Observations of two types of Pc 1-2 pulsations in the outer dayside magnetosphere, J. Geophys. Res., 107(A12), 1451, doi:10.1029/2001JA000198, 2002.

Engebretson, M. J., J. Moen, J. L. Posch, F. Lu, M. R. Lessard, H. Kim, and D. A. Lorentzen, Searching for ULF signatures of the cusp: Observations from search coil magnetometers and auroral imagers in Svalbard, J. Geophys. Res., 114, A06217, doi:10.1029/2009JA014278, 2009.

Fraser, B., Ionospheric duct propagation and Pc1 pulsation sources, $J$. Geophys. Res., 80(19), 2790-2796, 1975.

Greifinger, C. and P. S. Greifinger, Theory of hydromagnetic propagation in the ionospheric waveguide, J. Geophys. Res., 73(23), 7473-7490, 1968.

Hayashi, K., T. Yamamoto, S. Kokubun, T. Oguti, T. Ogawa, N. Iwagami, T. Araki, T. Kitamura, O. Saka, K. Makita, N. Sato, T. Watanabe, R. E. Horita, D. J. McEwen, J. S. Kim, and A. Egeland, Multi-station observation of IPDP micropulsations-Two-dimensional distribution and evolution of the source regions, J. Geomag. Geoelectr., 40, 583-619, 1988 .

Hebden, S. R., T. R. Robinson, D. M. Wright, T. Yeoman, T. Raita, and T. Bösinger, A quantitative analysis of the diurnal evolution of Ionospheric Alfvén resonator magnetic resonance features and calculation of changing IAR parameters, Ann. Geophys., 23, 1711-1721, 2005.

Kangas, J., A. Guglielmi, and O. Pokhotelov, Morphology and physics of short-period magnetic pulsations (a review), Space Sci. Rev., 83, 435512, doi:10.1023/A:1005063911643, 1998.

Kuwashima, M., T. Toya, M. Kawamura, T. Hirasawa, H. Fukunishi, and M. Ayukawa, Comparative study of magnetic Pc1 pulsations between low latitudes and high latitudes: Statistical study, Mem. National Inst. Polar Res., 18, 101-117, 1981.

Lessard, M. R., E. J. Lund, S. L. Jones, R. L. Arnoldy, J. L. Posch, M. J. Engebretson, and K. Hayashi, Nature of Pi1B pulsations as inferred from ground and satellite observations, Geophys. Res. Lett., 33, L14108, doi:10.1029/2006GL026411, 2006.

Lühr, H., The IMAGE magnetometer network, STEP International Newsletter, 4(10), 4-6, 1994.

Lysak, R. L., Generalized model of the ionospheric Alfvén resonator, in Auroral Plasma Dynamics, Geophys. Monogr. Ser., vol. 80, edited by R. L. Lysak, pp. 121-128, AGU, Washington, D.C., 1993.

Mann, I. R., D. K. Milling, I. J. Rae, L. G. Ozeke, A. Kale, Z. C. Kale, K. R. Murphy, A. Parent, M. Usanova, D. M. Pahud, E.-A. Lee, V. Amalraj, D. D. Wallis, V. Angelopoulos, K.-H. Glassmeier, C. T. Russell, H.-U. Auster, and H. J. Singer, The upgraded CARISMA magnetometer array in the THEMIS era, Space Sci. Rev., 141, 413-451, 2008.

Milling, D. K., I. J. Rae, I. R. Mann, K. R. Murphy, A. Kale, C. T. Russell,
V. Angelopoulos, and S. Mende, Ionospheric localisation and expansion of long-period Pi1 pulsations at substorm onset, Geophys. Res. Lett., 35 , L17S20, doi:10.1029/2008GL033672, 2008.

Miyoshi, Y., K. Sakaguchi, K. Shiokawa, D. Evans, J. Albert, M. Connors, and V. Jordanova, Precipitation of radiation belt electrons by EMIC waves, observed from ground and space, Geophys. Res. Lett., 35, doi:10.1029/2008GL035727, 2008.

Mursula, K., T. Bräysy, K. Niskala, and C. Russell, Pc1 pearls revisited: Structured electromagnetic ion cyclotron waves on Polar satellite and on ground, J. Geophys. Res., 106(A12), 29543-29553, 2001.

Parent, A., I. R. Mann, and K. Shiokawa, Observing the MLT and L-shell dependence of ground magnetic signatures of the ionospheric Alfvén resonator, Proc. Int. Conf. Substorms-8 (ICS-8), pp. 225-230, 2006.

Pilipenko, V. A., E. N. Fedorov, and M. J. Engebretson, Alfven resonator in the topside ionosphere beneath the auroral acceleration region, $J$. Geophys. Res., 107(A9), 1257, doi:10.1029/2002JA009282, 2002.

Pokhotelov, O. A., V. Khruschev, M. Parrot, S. Senchenkov, and V. P. Pavlenko, Ionospheric Alfvén resonator revisited: Feedback instability, J. Geophys. Res., 106, 25813-25824, 2001.

Polyakov, S. V. and V. O. Rapoport, Ionospheric Alfvén resonator, Geomagn. Aeron., 21, 610-614, 1981.

Posch, J. L., M. J. Engebretson, S. B. Mende, H. U. Frey, R. L. Arnoldy, M. R. Lessard, L. J. Lanzerotti, J. Watermann, M. B. Moldwin, and P. V. Ponomarenko, Statistical observations of spatial characteristics of Pi1B pulsations, J. Atmos. Sol.-Terr. Phys., 69, doi:10. 1016/j.jastp.2007.07.015, 1775-1796, 2007.

Russell, C. T., P. J. Chi, D. J. Dearborn, Y. S. Ge, B. Kuo-Tiong, J. D. Means, D. R. Pierce, K. M. Rowe, and R. C. Snare, THEMIS groundbased magnetometers, Space Sci. Rev., doi:10.1007/s11214-008-9337$0,2008$.

Sakaguchi, K., K. Shiokawa, A. Ieda, Y. Miyoshi, Y. Otsuka, T. Ogawa, M. Connors, E. F. Donovan, and F. J. Rich, Simultaneous ground and satellite observations of an isolated proton arc at subauroral latitudes, $J$. Geophys. Res., 112, A04202, doi:10.1029/2006JA012135, 2007.

Sakaguchi, K., K. Shiokawa, Y. Miyoshi, Y. Otsuka, T. Ogawa, K. Asamura, and M. Connors, Simultaneous appearance of isolated auroral arcs and Pc 1 geomagnetic pulsations at subauroral latitudes, $J$. Geophys. Res., 113, A05201, doi:10.1029/2007JA012888, 2008.

Sandanger, M., F. Søraas, K. Aarsnes, K. Oksavik, and D. S. Evans, Loss of relativistic electrons: Evidence for pitch angle scattering by electromagnetic ion cyclotron waves excited by unstable ring current protons, J. Geophys. Res., 112, A12213, doi:10.1029/2006JA012138, 2007.

Thorne, R. M. and C. F. Kennel, Relativistic electron precipitation during magnetic storm phase, J. Geophys. Res., 76, 4446-4453, 1971.

Troitskaya, V. A. and A. V. Guglielmi, Geomagnetic micropulsations and diagnostics of the magnetosphere, Space Sci.Rev., 7, 689, 1967.

Vellante, M., M. De Lauretis, U. Villante, N. Adorante, A. Piancatelli, K. Schwingenschuh, W. Magnes, W. Koren, and T. L. Zhang, A new meridional array in middle-south europe for monitoring dynamic processes in the coupled system plasmasphere-ionosphere, in SOLSPA 2001: Proceedings of the Second Solar Cycle and Space Weather Euroconference, ESA Spec. Publ. 477, edited by Sawaya-Lacoste, H., Eur. Space Agency, Noordwijk, Netherlands, 487-490, 2002.

Yahnin, A. G., T. A. Yahnina, H. U. Frey, T. Bösinger, and J. Manninen, Proton aurora related to intervals of pulsations of diminishing periods, J. Geophys. Res., 114, A12215, doi:10.1029/2009JA014670, 2009.

Yeoman, T. K., D. K. Milling, and D. Orr, Pi2 pulsation polarization patterns on the U.K. Sub-auroral Magnetometer Network (SAMNET), Planet. Space Sci., 38, 589-602, 1990.

Yumoto, K., and the 210MM Magnetic Observation Group, The STEP 210 magnetic meridian network project, J. Geomag. Geoelectr., 48, 12971310, 1996.

Yumoto, K. and the CPMN Group, Characteristics of Pi 2 magnetic pulsations observed at the CPMN stations: A review of the STEP results, Earth Planets Space, 53, 981-992, 2001.

Yumoto, K. and the MAGDAS Group, MAGDAS project and its application for space weather, in Solar Influence on the Heliosphere and Earth's Environment: Recent Progress and Prospects, edited by $\mathrm{N}$. Gopalswamy and A. Bhattacharyya, ISBN-81-87099-40-2, pp. 309405, 2006.

K. Shiokawa (e-mail: shiokawa@stelab.nagoya-u.ac.jp), R. Nomura, K. Sakaguchi, Y. Otsuka, Y. Hamaguchi, M. Satoh, Y. Katoh, Y. Yamamoto, B. M. Shevtsov, S. Smirnov, I. Poddelsky, and M. Connors 